\title{
Photonics: challenging diverse students in a flat world for emerging careers
}

Joyce Hilliard-Clark

Joyce Hilliard-Clark, "Photonics: challenging diverse students in a flat world for emerging careers," Proc. SPIE 9665, Tenth International Topical Meeting on Education and Training in Optics and Photonics, 96651 U (3 June 2007); doi: $10.1117 / 12.2207804$

SPIE Event: Tenth International Topical Meeting on Education and Training in Optics and Photonics, 2007, Ottawa, Ontario, Canada 


\title{
Photonics: Challenging Diverse Students in a Flat World for Emerging Careers
}

Joyce Hilliard-Clark et al

\author{
North Carolina State University Imhotep Academy \\ Raleigh, NC
}

The Photonics program addresses the question of how does one integrate scientific content, student encouragement, and parental support to engage minority high school students to experience success in areas of a national need? Historical data indicates that ethnically diverse students, (African Americans), do not take advanced mathematics and science, (physics), courses in high school. Therefore, we propose using a variety of strategies for providing instruction in leadership, experimentation, research writing, communication and scientific presentation to work with students, families and teachers in promoting success and academic achievement in challenging science courses. Seventy-five African American students are participating in a yearround Photonics (physics of light) program at NC State University. Students from fifteen counties in North Carolina learn about fiber optics, communications and the properties of light.

Objectives: Participants develop a deeper and richer understanding of science, technology, engineering and mathematics, to improve students' competencies in science and to nurture their interest in science, technology, engineering and mathematics (STEM) careers.

Methods: Photonics students investigate the technology they encounter routinely. Students built telescopes, laser diode circuits, electronic robots and carry out scientific research using lasers and other photonics devices in biweekly and monthly sessions.

Results: The program has done a stellar job of targeting minority students. Seventy-five percent African American, nine percent Asian/Pacific Islander, 14 percent Caucasian and two percent Hispanic are participants. Forty-six percent are male and 54 percent female. Ninety-one percent of the students experienced a successful encounter and have a better understanding of photonics according to BWF SSEP Student Feedback Survey.

Conclusion: Using qualitative data collected from surveys, focus group interviews, pre- and post- assessments guide our research approach. Participants, (88 percent), have improved in writing, presentation skills and physics knowledge. The Photonics program continues to guide and expose under-represented students into a discipline traditionally not experienced in the public school setting, by making physics and photonics concepts authentic and relevant through handson technology learning experiences. Students have explored the world of work in their jobshadowing experiences and have learned from scientists in the university and community. Parents, teachers, students and the general public benefits from the outcomes of this program. 